\title{
INFORMATION TECHNOLOGY AND THE GOOD LIFE
}

\author{
Erik Stolterman \\ Anna Croon Fors \\ Umeå University
}

\begin{abstract}
The ongoing development of information technology creates new and immensely complex environments. Our lifeworld is drastically influenced by these developments. The way information technology is intertwined in our daily life raises new issues concerning the possibility of understanding these new configurations. This paper is about the ways in which IS research can contribute to a deeper understanding of technology and the ongoing transformations of our lifeworld. As such, the paper is a conceptual exploration driven by a sincere and authentic desire to make a real difference in the way research on how technology influences our society is carried out. The article is based on the assumption that there are some foundational decisions forming research: the question of methodology, the question of object of study, and, most importantly, the question of being in service. In the paper we explore and propose a research position by taking a critical stance against unreflective acceptance of information technology and instead acknowledge people's lifeworld as a core focus of inquiry. The position is also framed around an empirical and theoretical understanding of the evolving technology that we label the digital transformation in which an appreciation of aesthetic experience is regarded to be a focal methodological concept.
\end{abstract}

Keywords: Information systems research, critical theory, aesthetic experiences, digital transformation, device paradigm, information technology

\section{IN SERVICE OF THE GOOD LIFE}

The ultimate concern for most people is to have the opportunity and capacity to live a "good life." What might constitute a good life is, of course, as difficult to define as it is to characterize basic human needs and desires. Nevertheless, in this paper we argue that information systems research should, as at least one of its intentions, create and 
formulate knowledge that can help people understand and reflect on their place and situation in the midst of an ongoing technological revolution. We argue that one purpose of IS research should be to explore, experiment, test, analyze, examine, explain, and reflect on how information technology can be in service of the good life. Such a purpose, even if vague, would strongly influence the way research is carried out.

An information systems researcher is always in service to someone or something. Ideally, as a researcher, you should be in service to the truth, and you should do this by producing true knowledge. Our contemporary research environment is, however, more complicated due to a long and intricate questioning of truth as the only objective and final goal. So, to have truth as the client has, over time, been complemented with other potential clients, leading to objectives such as organizational and/or personal efficiency and improvement, or detailed technological solutions to more specific and narrow, real or imagined problems.

We argue that a neglect of the "big" issues leads to a situation where people cannot get enough help in their everyday struggle to understand and make meaning of their rapidly changing lifeworld. Also, it seems as though people assume information technology to be the solution for prosperity and continuous development, while at the same time they hold technological artifacts to be a bearer of something that contradicts what they see as the core of a good life. So, while there is a strong general acceptance of information technology, there is also a fear that it will force us into a way of living that we cannot handle or do not really want.

This is a real challenge for IS research. It is a challenge that demands a creative design of the very foundation for information systems research. Such a design can be understood as a research position. In this paper we propose such a research position based on a critical stance against unreflective acceptance of information technology. We also propose, based on that position, the notion of the digital transformation as a way of framing a suitable object of study, and the idea of aesthetic experience as a base for a methodological approach.

\section{ESTABLISHING A RESEARCH POSITION}

Recently there has been an intensified debate on the status and future of information systems as an academic research discipline (Benbasat and Weber 1996; Benbasat and Zmud 2003; Holmström and Truex 2003; Orlikowski and Iacono 2001; Walsham 1993; Weber 2003).

In this debate, two of the most discussed issues are the question of methodology and the question of what constitutes the object of study. In this paper we also address a third assumption - the question of service - as mentioned in the introduction.

It has lately been advocated that being in service constitutes a distinct kind of relationship (Nelson and Stolterman 2003). If such a relationship is taken seriously, any decision of who is the major client establishes a clear position for IS research, a position that makes it possible to see what the purpose of the research is as well as governs what should be studied, why it should be studied, and, perhaps most important, brings a value system from which the research outcome is measured and judged as valid or not.

When a researcher decides on how to relate to the three foundationsmethodology, object of study, and service-a unique research position is created. Even 
though there are several kinds of positions in IS research today, we claim that the possibilities of positions are far from being fully explored.

The basic idea in our proposal is that the most crucial challenge for IS research today is the study of the overall effects of the ongoing digital transformation of society. The digital transformation can be understood as the changes that the digital technology causes or influences in all aspects of human life. This research challenge has to be accepted on behalf of humans, not in their role as users, customers, leaders, or any other role, but as humans living a life. In this respect we argue that IS research must accept the challenge to overcome the predominating "one-dimensionality" in the understanding of information technology (Marcuse 1964). The position we argue for is based on the assumption that the digital transformation is the core object of study for IS research. As such, IS researchers should, instead of examining information technologies as separable and as defined along one single dimension, consider them as being a part of a greater whole. This is also expressed in some recent theories framing technological development as information ecologies, collective intelligence, and actor networks, which are more sensitive to the various ways in which information technology is entering our lives (Feenberg 1999; Latour 1993; Levy 1997; Nardi and O’Day 1999).

The suggested position is also based on the assumption that the way to study the digital transformation demands a methodology capable of reflecting the relatedness of information technology to such a larger whole. We propose an approach influenced by critical theory with the notions of the device paradigm and aesthetic experience as focal concepts.

\section{THE DIGITAL TRANSFORMATION AND ITS CRITICAL BASE}

A central aspect of information systems research is the underlying technology providing the basis and ground for any information system. We all experience in our everyday lives that information technology becomes more common and present in almost every part of our doings. We find ourselves using IT artifacts at work, in our homes, and when we exercise our hobbies. The technology is not only manifesting itself through individual IT artifacts (such as computers, software applications, PDAs, mobile phones, etc.); it also blends itself into most other artifacts. As such, information technologies are increasingly becoming embedded in all other objects.

This leads to a world that is increasingly experienced with, through, and by information technology. What we are witnessing is an ongoing radical digital transformation.

One of the most important changes that come with the digital transformation is that our reality by and through information technologies slowly becomes more blended and tied together. Designed objects will be parts of systems and networks where they will, or at least can, be in constant communication with all other parts and objects. These new realities, new systems, are of course designed but, at another level, they can be seen as evolving entities, where local designs contribute to systemic changes in a larger network. The notion that every design adds a new part to our reality will have a new and truer meaning.

New artifacts are not just adding to what already exists; they are also becoming indistinguishable from the whole. An increasing problem is knowing where one context 
and/or design begins and another ends. The digital transformation leads in that sense to a world where everything is connected, almost in a way that is common in many spiritual understandings of our reality.

Yet another important aspect of the transformation appears as digital objects become the basic materials in our physical reality. When this is the case the physical reality will to some degree become intelligent. Designed objects will have the power to inform themselves and the network they belong to about changes and the status of their environment and actions taken upon them by humans and other objects. This adds a new dimension to the notion of the reflexivity of information technologies. The way humans experience their lifeworld, largely influenced by digital technology, is not as separate entities that might be user-friendly or not, but as a lifeworld, as a whole. To understand this aspect of information technologies and information systems will become ever more difficult. To do it by analyzing them individually and/or by using reductionistic methods will be impossible.

At the same time, the device paradigm, portrayed by Borgmann (1984, 1999), pushes us to an understanding of technology as providers of commodities, designed to grant our wishes without demanding any patience, skill, or effort. Rather, the world is taken up in an instrumental and effective fashion by technological artifacts and systems that are not designed to be experienced in an active and signifying way. The device paradigm leaves us focused on the outcomes that technology provides rather than make us concerned with the way we experience reality as a whole. Information technology and the digital transformation seem to be the perfect tools for the device paradigm to be manifested.

In such a paradigm, according to Borgmann, there are important concerns and values that are being threatened, concerns that are necessary in order for people to live a good life. Experiences of what it means to live a good life are, of course, both infinite and complex. They are also experiences that are analog to their character in that the world is experienced as one and in a continuum. In such experiences, information technologies are not separated from anything else but seamlessly interwoven in a complex and complete web ofmeaning. To researchers with the ambition to understand the ways in which people create meaning of their realities and how information technologies transforms this process, this creates several challenges and opportunities.

One challenge inherent in the digital transformation is that information systems researchers today need to develop approaches, methods, and techniques to the study of information technology that are not based on an analytic and reductionistic stance. Another challenge, as a consequence of the device paradigm, is to take an active stance against a development leading to an everyday reality dominated by commodities, i.e., technological artifacts as described in the device paradigm.

In the attempt to take up this challenge we advocate the notion of aesthetic experiences as one possible conceptual candidate to further advance. While traditional approaches are suffering from the fact that the more complex reality becomes, the more time is needed for analysis, an approach based on the notion of the aesthetics experience makes it possible to take the whole and the immediate into account and to deal with complexity and meaning-making at another level. Since information technology is part of people's experienced life, their lifeworld, the aesthetic experience becomes a way to measure their understanding of their life in relation to the good life. 
The critical stance expressed in the use of the notion of aesthetic experience is a creative and radical approach, aiming for the inherent potentiality of information technology (Marcuse 1964). We believe that a focus on the aesthetic experience is one way to find and explore creative abstractions that reveal reality in new ways. As Marcuse writes,

Such abstraction which refuses to accept the given universe of facts as the final context of validation, such " transcending" analysis of the facts in the light of their arrested and denied possibilities, pertains to the very structure of social theory.

If we accept the challenge that we as information systems researchers have to grasp the way information technology changes people's lifeworld, we need conceptual tools that have the necessary scope and strength. We believe that the concept of aesthetic experience, as developed within the philosophical traditions of critical theory and pragmatism among others, is a suitable candidate. Of course, it has to be further developed as a theoretical tool, but this may be more as a fundamental methodological approach. This work is not done and will be a major task in the development of the research position we are suggesting.

\section{TOWARD A RESEARCH POSITION}

One of the assumptions underlying our argumentation has been that there is a need for a critical stance, a research approach that advances the idea that technology can be critically examined in the search for the good life. We have defined such a research position as being manifested by the intentional choice and definition of methodology, object ofstudy, and service. Without neglecting other commonly held positions, we have proposed one research position as especially needed today when digital and device transformations are changing the preconditions for our possibilities to live a good life.

We believe that information systems research is better suited than most other academic disciplines to take on this position. However, as long as research in our field is not taking this as a serious challenge, the outcomes continue to be an efficient support of the ongoing device transformation leading us to a place were we might not want to go.

Our work has been guided by a desire to take on the big issue by taking seriously the question of being in service of people trying to live a good life. It is, of course, too grand a project for a single researcher or research group. At the same time, as researchers, we cannot yield to the important issues because we believe they are not researchable. The overall issue on how information technology, on a fundamental level, influences our lives is maybe the most crucial issue today. This paper is an attempt to establish a research position suitable as a starting point for such studies.

\section{REFERENCES}

Benbasat, I., and Weber, R. "Research Commentary: Rethinking 'Diversity' in Information Systems Research," in Information Systems Research (7:4), December 1996, pp. 389-399. 
Benbasat, I., and Zmud, R. “The Identity Crisis Within the IS Discipline: Defining and Communicating the Discipline's Core Properties," MIS Quarterly (27:2), 2003, pp. 183-194.

Borgmann, A. Holding on to Reality: The Nature of Information at the Turn of the Millenium, Chicago: The University of Chicago Press, 1999.

Borgmann, A. Technology and the Character of Contemporary Life: A Philosophical Inquiry, Chicago: The University of Chicago Press, 1984.

Feenberg, A. Questioning Technology, London: Routledge, 1999.

Holmström, J., and Truex, D. "Social Theory in IS Research: Some Recommendations for Informed Adaption of Social Theories in IS Research,” in J. Ross and D. Galletta (Eds.), Proceedings of the $\mathbf{9}^{\text {th }}$ Americas Conference on Information Systems, Tampa, 2003, pp. 2850-2856.

Latour, B. We Have Never Been Modern, Cambridge, MA: Harvard University Press, 1993.

Levy, P. Collective Intelligence: Mankind's Emerging Worldin Cyberspace, New York: Plenum Trade, 1997.

Marcuse, H. One Dimensional Man: Studies in the Ideology of Advanced Industrial Society, Boston: Beacon Press, 1964.

Nardi, B. A., and O'Day, V. L. Information Technologies: Using Technology with Heart, Cambridge, MA: MIT Press, 1999.

Nelson, H., and Stolterman, E. The Design Way-Intentional Change in an Unpredictable World, Englewood Cliffs, NJ: Educational Technology Publishing, 2003.

Orlikowski, W., and Iacono, C. S. "Research Commentary: Desperately Seeking the 'IT' in IT Research-A Call to Theorizing the IT Artifact," In Information Systems Research (12:2), 2001, pp. 121-134.

Walsham, G. Interpreting Informations Systems in Organizations, Chichester, England: Wiley, 1993.

Weber, R. "Editor's Comment: Still Desperately Seeking the IT Artifact," MIS Quarterly (27:2), 2003, pp. iii-xi.

\section{ABOUT THE AUTHORS}

Erik Stolterman is a member of the Department of Informatics, Umeå University, Sweden. His main work is within information technology and society, information systems design, philosophy of design, and philosophy of technology. Erik is also one of the founders of The Advanced Design Institute. Apart from the academic scholarly work, Eric is engaged in consulting, seminars, and workshops with organizations and companies. He can be reached at erik@informatik.umu.se or http://www.informatik.umu.se/ erik/.

Anna Croon Fors is a Ph.D. student and instructor at the Department of Informatics, Umeå University, Sweden. In her forthcoming dissertation, Anna analyses the meaning and consequences of information technology in people's everyday life through the phenomenological notion of "being." Her research interest covers IT use in various social settings in search of a foundation for critically oriented research beyond the common notions of either use and design. She can be reached at acroon@informatik.umu.se. 